reinforcement in the other are identified as the moving agents. This parallel still has some reality, but it would have been fair to point out that other authors, more recent than Descartes, had dealt with it in some detail (e.g. Pringle 1951). The comparison of the outcomes of schedules of reinforcement with the effect of schedules of selection that might have been illuminating re-

\section{Consequence contingencies and provenance partitions}

\author{
Juan D. Delius \\ Experimentelle Tierpsychologie, Psychologisches Institut, Ruhr-Universität, \\ 4630 Bochum, Federal Republic of Germany
}

When, about 15 years ago, I had to prepare a lecture intended to inform a conference of neuroscientists about the views of ethologists on the development of behavior, I thought it would be a good idea to contrast these views with those of behaviorists. One of the themes I thought of featuring was the behaviorists' Olympian disregard of biological evolution. The title of the lecture was going to be "The Phylogeny of Behavior Ontogeny." My dismay was great when idly leafing through a pile of Science issues left by my office predecessor I stumbled upon B. F. Skinner's "Phylogeny," There was the preeminent theoretician of behaviorism holding forth on the very topic I supposed he and his brethren chose to ignore. I quickly modified both the tack and the title of my presentation (Delius 1970).

However, as laudable as I found Skinner's late interest in evolution, I was disappointed by "Phylogeny." It was neither a source of theoretical inspiration nor a reflection of the state of the art. On the contrary, it seemed intent on reversing hardwon progress. It reified in the guise of "ontogenic behavior" and "phylogenic behavior" the strict dichotomy between innate and learned behavior, a division that even ethological diehards had by then been forced to give up. All the arguments and the evidence against such a black-or-white distinction that had been marshaled by then (see Hinde 1966; Marler \& Hamilton 1966) seemed to have bypassed Skinner. A rigid commitment leads him to equate behavioral on togeny exclusively with the changes of response probabilities due to reinforcement contingencies, that is, with operant conditioning. Not even classical conditioning is expressly acknowledged to play a role in the development of behavior. Imprinting is, summarily and wrongly, dismissed as just another instance of operant conditioning. Nonlearning influences of environmental variables on the ontogeny of behavior are ignored. The provenance of "ontogenic behavior" is simply and purely operant conditioning and nothing else.

In contrast, Skinner ascribes the provenance of "phylogenic behavior" to the contingencies of natural selection acting upon a collection of fixed action patterns and does not allow it any ontogeny. This is logically consistent within his conceptual framework but ignores the fact that it conflicts with the evidence then already extant. That phylogeny exerts control over behavior via ontogeny and through genes is conveniently ignored. Behavior genetics is all but dismissed on the technical ground that its results do not square with Skinner's expectation that genes should express themselves in "units" of behavior.

Conversely, "ontogenic behavior" apparently does not have a phylogeny except that Skinner admits obliquely that baseline responding and certain reinforcers may have an evolutionary provenance. Considering that Skimer equates ontogeny with operant conditioning, that might be a fair reflection of contemporary behaviorist opinion. But there were already signs that it would not endure (Garcia \& Koelling 1966). Following earlier ethological suggestions (Lorenz 1965; Tinbergen 1951) it soon became apparent that the phylogeny of learning is a more complex and incisive issue (Seligman 1970).

Instead, attention is drawn to the analogy that exists between the processes underlying phylogeny and ontogeny (sensu Skinner). Contingencies of selection in one case and contingencies of mains superficial; Skinner, perhaps sensing that it would have shown up the limitations of the analogy, chose not to find out what evolutionary biologists had to say about the matter. The exciting possibility of an "experimental analysis of phylogenic behavior" is surprisingly negated by alluding to natural selection's action in the unrecoverable past. Artificial selection is unnatural and thus deemed not really relevant. Ad hoc pleading is then necessary to immunize from a similar criticism artificial reinforcement, the basis of what should now correctly be the "experimental analysis of ontogenic behavior." Arguably, the failure to provide objective, as opposed to hypothetical, accounts of the natural ontogeny of behaviors as a product of natural reinforcement contingencies was already in 1966 corroding the attractiveness of radical behaviorism.

Why has the paper had so little impact, even among Skinner's own following? It is simply that the attempt to contain the explosion of knowledge that had in the meantime occurred within the very lean ontological framework conceived some 30 years earlier (Skinner 1938) yielded an inadequately narrow account. It could not compete against the up and coming eclectic, much richer, multidisciplinary account of behavior (Delius 1985), which, to be sure, incorporates a great deal of what Skinner and his disciples have discovered and described with truly admirable acumen. The sad fact is that simplicity, contrary to widespread opinion, is not a principle that organisms often care to respect.

\section{ACKNOWLEDGEMENT}

The preparation of this commentary was supported in part by the Deutsche Forschungsgemeinschaft through its Sonderforschungsbereich 114 . 